\title{
New Spectral Markers for Broken Bars Diagnostics in Induction Motors
}

\author{
Georgii D. Baranov ${ }^{1}$, Erivelton G. Nepomuceno ${ }^{2}{ }^{\circledR}$, Michail A. Vaganov ${ }^{1}$, \\ Valerii Y. Ostrovskii ${ }^{3}$ id and Denis N. Butusov ${ }^{4, *}$ (D) \\ 1 Department of Robotics and Industrial Systems Automation, \\ Saint Petersburg Electrotechnical University "LETI", Professora Popova 5, 197376 Saint Petersburg, Russia; \\ gdbaranov@stud.etu.ru (G.D.B.); ma.vaganov@yandex.ru (M.A.V.) \\ 2 Control and Modelling Group (GCOM), Department of Electrical Engineering, \\ Federal University of São João del-Rei, São João del-Rei MG 36307-352, Brazil; nepomuceno@ufsj.edu.br \\ 3 Department of Computer-Aided Design, Saint Petersburg Electrotechnical University "LETI”, \\ Professora Popova 5, 197376 Saint Petersburg, Russia; vyostrovskii@etu.ru \\ 4 Youth Research Institute, Saint Petersburg Electrotechnical University “LETI”, Professora Popova 5, \\ 197376 Saint Petersburg, Russia \\ * Correspondence: dnbutusov@etu.ru; Tel.: +7-950-008-7190
}

Received: 11 December 2019; Accepted: 27 January 2020; Published: 28 January 2020

\begin{abstract}
The paper discusses the spectral markers of fault rotor bars in induction motor current signature analysis (MCSA). The results of the simulation of the deterioration process for a single rotor bar, as well as the results of research for various mutual bracing of two broken bars, are reported. We proposed a simple empiric technique allowing one to obtain frequencies for spectrum markers of damaged rotor bars based on simulation analysis. The set of frequencies obtained in the experimental part of the study was compared with simulation results and the results of real-life measurements. The theoretical results were verified through the experiment with the real induction motor under load. Analysis of experimental results proved that the given algorithm for spectrum analysis is suitable for early detection of fault rotor bars in induction motors.
\end{abstract}

Keywords: rotor bar fault; induction machine; finite-element analysis; motor current signature analysis

\section{Introduction}

Induction motors are widely applied in industry, transport, and construction. During the manufacturing process and exploitation of vehicles, defects in electrical machines appear. By nature of influence for the machine, work defects can be divided into two groups: The "emergency cases" and the defects of state. The first type of defects usually leads to failure in a short time. These defects include the interterm short circuit in stator winding or phase break of the stator. The modern control systems of work induction motor drive have protection subsystems from most common emergency defects.

Defects of the second type slightly change the machine operating parameters without causing its failure in a relatively short term. Such defects include rotor eccentricity, bearing defects, insulation degradation, broken rotor bars, etc. The common method for detecting this type of defect is vibration analysis. Escaler and Mebarki [1] investigated frequency markers of wind turbines damage. The given comparison between the reference mean vibration acceleration values of the gear mesh frequency and its harmonics shows that progressive damage causes a specific vibration pattern. Moreover, the amplitude of upper harmonics grows faster than the amplitude of lower harmonics with the growth of damage level. Luwei et al. used the vibration data of rotating machines acquired at different speeds to detect various faults by artificial neural networks (ANN) [2]. The algorithm processes measured 
vibration data from multiple sensors installed on the rotating machine and generated features for fault diagnostics representing the dynamic behavior of the entire machine. The extracted features were further processed using ANN to make a final decision on the condition of the machine.

Villarroel et al. [3] proposed the vibration measurement system for machine diagnostics, including electrical motors. The authors concluded that there is a significant need for a low-cost solution collecting vibration data from the industrial machines, storing and transferring it to a computer for processing. However, the vibration diagnostics still need sensors installed on the machine body. Almost any modern electric drive has built-in current sensors, so using them for diagnostics will be the most economical solution.

Hsueh et al. proposed an approach for condition monitoring based on the combination of recurrence analysis and neural networks used to interpret recurrence data [4]. In the first stage, 3-phase current signals were transformed into 2D texture images. In the second stage, the texture images were classified by the convolutional neural network. The proposed framework was implemented for four types of faults including bearing axis deviation, stator and rotor friction, rotor-end ring break, and poor insulation.

Wang et al. used involving cyclic modulation spectral analysis to detect broken rotor bars, which appear to be one of the most common causes of inductive motors faults [5]. The given method is based on vertical vibration signature analysis resulting in an improved cyclic modulation spectrum (CMS). The authors declared that the proposed method showed high noise immunity and accuracy.

The creation of a diagnostic system for state defects based on the analysis of current characteristics was actively carried out by many research teams [6-13], including the Zhukovsky group [14-17]. However, the correct and trustworthy fault markers are still to be developed. This gives us the motivation for the current study, where we provide detailed research on this issue. Despite various contradictions, the following discussion appears in many studies.

Let currents, generated by the rotating field of the stator winding on rotor winding, have frequencies $s f_{1}$, where $s$ is a rotor slip and $f_{1}$ is line supply frequency. While the rotor is a symmetric system of conductors with current, it generates a rotating magnetic field with frequency $s \omega_{1}$. The appearance of the fault in one of the bars of symmetric rotor winding induces a symmetry break in the rotating magnetic field. Therefore, the rotating rotor magnetic field appears in the reverse direction. The field rotates over a relatively static stator with the frequency $\left.\omega_{\mathrm{opp}}=\omega_{\mathrm{m}}-s \omega_{1}=\omega_{1}-s \omega_{1}\right)-s \omega_{1}=$ $\omega_{1}(1-2 s)$, and induces currents in stator winding with frequency $f=f_{1}(1-2 s)$. Currents with this frequency are usually considered as rotor bar fault markers.

Several studies show that other frequencies can be used as bar fault markers. The authors of [9-11] consider the influence rotor bars' fault on its magnetomotive force (MMF). As a result, the appearance of harmonics with the following frequencies is predicted:

$$
f=\left[\left(\frac{\eta}{p} \mp v\right)(1-s) \pm 1\right] f_{1}
$$

where $p$ is the quantity of poles pairs, $v$ is the number of the spatial harmonic, and $\eta$ is the integer coefficient.

In $[12,13]$, the authors proposed to distinguish harmonics with frequencies

$$
f=(1 \pm k s) 2 n f_{1}\left\{\begin{array}{l}
k=1,2,3, \ldots \\
n=1,2,3, \ldots
\end{array}\right.
$$

where $n, m$ are the integer coefficients. These frequencies are identified to be in range of 0 to $400 \mathrm{~Hz}$.

Tang et al. [18] discovered these harmonics but did not provide any mathematical generalization of them. Li [19] and Wang [5] analyzed only the low $(0-50 \mathrm{~Hz})$ frequencies. The great variety of abovementioned theories provides us the basis for this study. The aim of our work was the detailed study of the effect of rotor fault on the spectral composition of stator currents. 


\section{Materials and Methods}

There are several known approaches to simulate the processes in the short-circuited rotor of the asynchronous engine. Tang et al. [20] used a multiple-coupled-circuit method. This method allows analyzing the processes in the rotor through the solution of differential equations. However, to obtain these equations one needs to estimate the relative inductances between all the inductors in the circuit, which is no easy task itself. Gyftakis et al. [21] used finite elements to estimate the influence of the rotor's defect to the electromagnetic moment of the motor. This approach, along with the already discussed MMF method [9-11], is of great interest, but possesses a lot of assumptions to be applied. Thus, we chose the finite element method (FEM) to study the influence of asymmetry of the rotor field to the stator currents, which is a well-known approach for modeling electrical machines realized in ANSYS Maxwell. One can see the simulation of induction motor 4A132S4 with 25\% fault rotor bar in Figure 1.

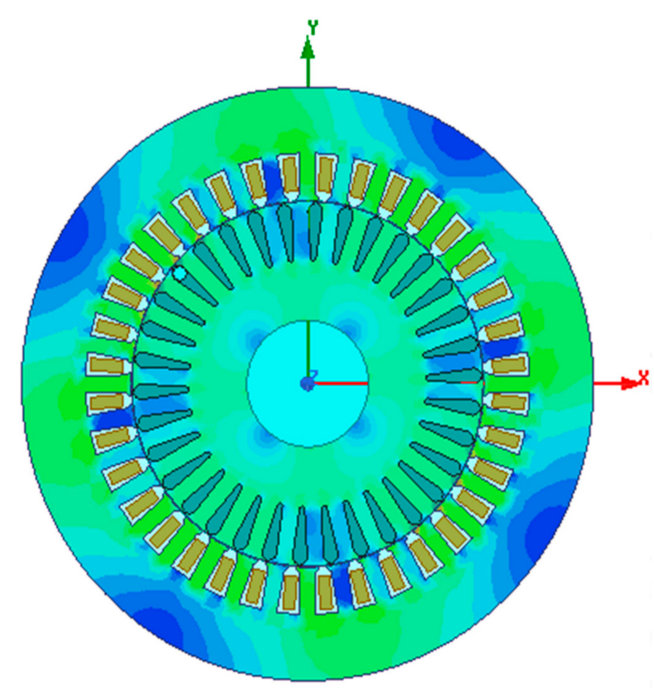

Figure 1. The induction motor 4A132S4 with 25\% fault rotor bar, simulated in ANSYS Maxwell.

The simulation of breakage bars in a short-circuited rotor winding was performed for the engine 4A132S4 [4], which possessed the following parameters:

- $\quad$ Engine rated power, $7.5 \mathrm{~kW}$;

- $\quad$ Rated voltage, $380 \mathrm{~V}$;

- $\quad$ Power supply frequency, $50 \mathrm{~Hz}$;

- Number of poles, 4;

- Outer diameter of the stator core, $225 \mathrm{~mm}$;

- Inner diameter of the stator core, $145 \mathrm{~mm}$;

- The length of the stator core, $115 \mathrm{~mm}$;

- Outer rotor core diameter, $144.3 \mathrm{~mm}$;

- Shaft diameter, 50 mm;

- Number of rotor slots, 34;

- $\quad$ Number of stator slots, 36.

In this simulation, we introduced the fault in the rotor bars by reducing their active sections. To compute the stationary state of the faulted machine we used the transient simulation mode, obtaining the stator phase current as a result.

Next, we processed the resulting current with the spectral analysis and denoising algorithm (please see [22] for further details). This approach allows us to filter the white noise from the signal. This is a recursive algorithm consisting of three repeated steps. First, one needs to measure the signal 
and identify its harmonic composition through the fast Fourier transform (FFT). Second, we need to find the sample with maximum amplitude and specify the frequency of the harmonic through the discrete-time Fourier transform. Then, this harmonic is removed from the signal and its frequency and amplitude are written in the resulting array. Finally, when the amplitude of maximum harmonic does not exceed the noise level, which is estimated before launching the filtering process, the algorithm stops. The adjustable parameter of the algorithm is the precision coefficient, which determines the sensitivity of preset noise level estimation. However, this algorithm can be affected by the phase noise close to the main harmonic, so one can observe a cluster of harmonics in this area caused by this noise. In further analysis, we did not consider this. The current spectrum was given in decibels for convenience of comparison and was normalized relative to the level of main harmonic.

\section{Results}

\subsection{Finite Element Modeling}

\subsubsection{The Simulation of The Bar Fault}

The first series of computer simulations were aimed at modeling the wearing process of bar short-circuited rotor winding. For this purpose, its cross-section was decreased by 25, 50, and 100\%. In all experiments, the slip value was set as $s=0.05$. The time step was $0.0001 \mathrm{~s}$. In Figure 2 the spectrum of phase stator current for different degrees of bar wear is presented. One can see that when increasing the wear of the bar, the certain frequencies of phase current spectrum in stator winding grew. The largest increase in amplitude can be observed at frequencies 45, 240, 330, 525, 615, 810, and $900 \mathrm{~Hz}$. Each of the listed frequencies possessed a group of side frequencies which varied in size but their amplitudes were inferior to the first.

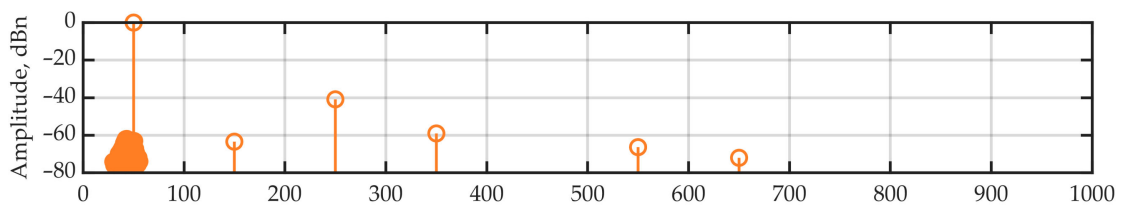

(a)

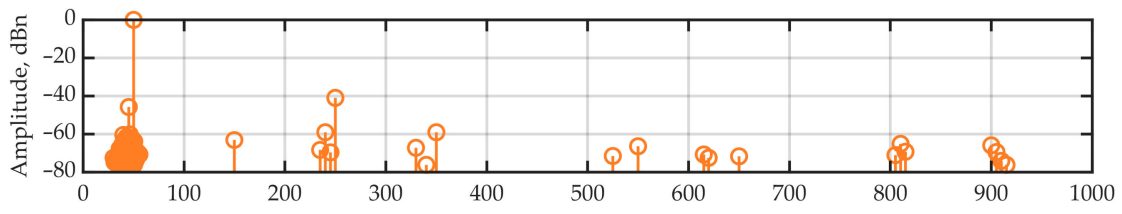

(b)

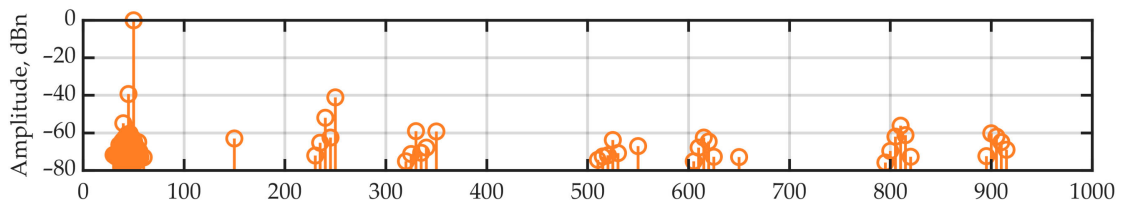

(c)

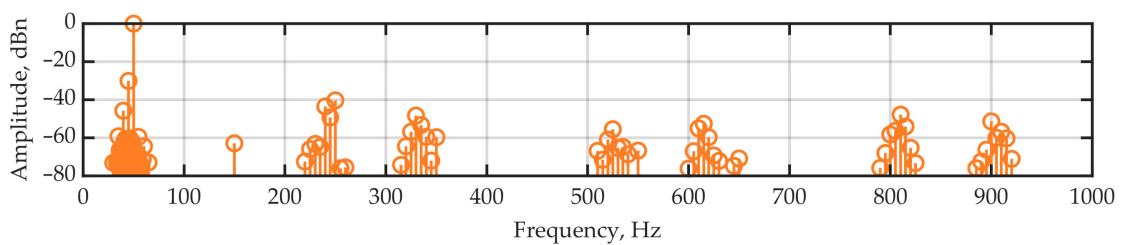

(d)

Figure 2. The spectrum of phase stator current for different degree of bar wear: (a) Fully functional "squirrel-cage" structure, (b) 25\% bar section fault, (c) 50\% bar section fault, (d) $100 \%$ bar section fault. 
From the resulting array, only one harmonic is described by the equation $f=f_{1} \cdot(1-2 \mathrm{~s})=50$. $(1-2 \cdot 0.05)=45 \mathrm{~Hz}$. For describing the rest of the harmonics engine, we performed the simulation with a completely broken bar with several values of slip: $0.02,0.05$, and 0.07 . In Figure 3 , one can see the sector of the spectrum of stator current for completely broken rotor bar in the range from $850 \mathrm{~Hz}$ to $950 \mathrm{~Hz}$ for various values of slip. In Figure 2, this sector is allocated. From the plots, the change in slip led to a change in the spectrum. While slip value decreased, the harmonics belonging to the same group tended to "shrink", and the frequency intervals between them were reducing. With an increasing slip value, the opposite behavior was observed.

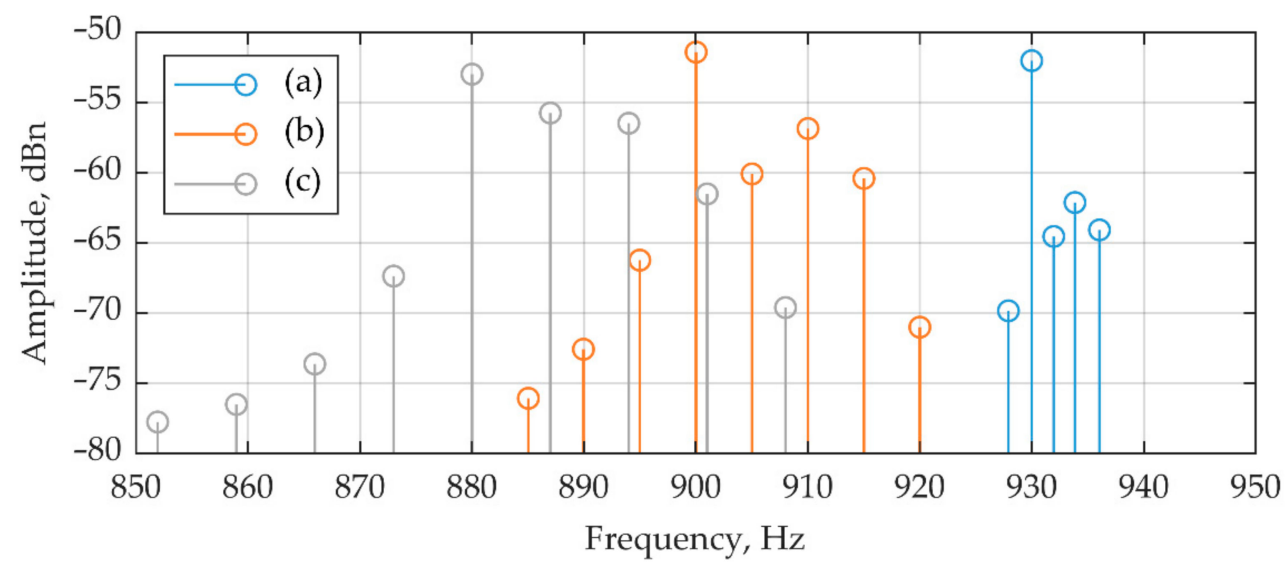

Figure 3. The spectrum of stator current for completely broken rotor bar. (a) Rotor slip is 0.02 , (b) rotor slip is 0.05 , (c) rotor slip is 0.07 .

Despite the intervals between harmonics change, in any case there was a harmonic with the largest amplitude. Frequencies with the largest amplitude increased for $s=0.02$ were 48, 246, 342, 540, 636, 834, and $930 \mathrm{~Hz}$, respectively, and for $s=0.07$ were 43, 236, 322, 515, 601, 794, and $880 \mathrm{~Hz}$.

\subsubsection{Empirical Evaluation}

Following the analogy with an equation for reference frequency near the main spectrum harmonic $f=f_{1} \cdot(1-2 \cdot s)$, one can notice that indicated frequencies can be generalized by the following expressions:

$$
\left\{\begin{array}{l}
f=f_{1}(v-(v+\alpha) s), \quad v=1,7,13,19 \ldots \\
f=f_{1}(v-(v-\alpha) s), \quad v=5,11,17 \ldots
\end{array} \quad \alpha=\ldots-5,-3,-1,1,3,5 \ldots,\right.
$$

where $f_{1}$ is line supply frequency, $v$ is integer coefficient that is relevant to the numerical order of rotating spatial harmonics of MMF stator winding, and $\alpha$ is integer odd coefficient relevant to the numerical order of time harmonics of stator current.

The frequencies described by Equation (3) can be divided into seven groups. For each group, one can select the primary frequency having the greatest amplitude $(\alpha=1)$ and several secondary ones located near the primary one.

Groups were formed by the reference to value coefficient $v$, corresponding to the numbers directly or backward rotating spatial harmonics of MMF stator winding. Thus, harmonics 7, 13, and 19 were rotating in accordance with the first harmonic and refer to straight rotating, and harmonics 5, 11, and 17 rotated in the opposite direction and referred to reverse rotating [15].

In Table 1, the frequency values determined by the Equation (3) for each of the seven groups are given. The harmonics that were marked by an increase in amplitude when modeling the breakage of two consecutive bars (Figure 4a) are marked orange. Blue color corresponds to harmonics that were marked by an increase in amplitude in experiments with the real motor. The orange with blue shading corresponds to the harmonics that were detected in both experiments. 
Table 1. Reference frequencies in Hz, obtained from Equation (3) for slip value $s=0.05$.

\begin{tabular}{cccccccc}
\hline $\boldsymbol{\alpha}$ & $\boldsymbol{v}=\mathbf{1}$ & $\boldsymbol{v}=\mathbf{5}$ & $\boldsymbol{v = \mathbf { 7 }}$ & $\boldsymbol{v}=\mathbf{1 1}$ & $\boldsymbol{v}=\mathbf{1 3}$ & $\boldsymbol{v}=\mathbf{1 7}$ & $\boldsymbol{v}=\mathbf{1 9}$ \\
\hline-11 & 75 & 210 & 360 & 495 & 645 & 780 & 930 \\
-9 & 70 & 215 & 355 & 500 & 640 & 785 & 925 \\
-7 & 65 & 220 & 350 & 505 & 635 & 790 & 920 \\
-5 & 60 & 225 & 345 & 510 & 630 & 795 & 915 \\
-3 & 55 & 230 & 340 & 515 & 625 & 800 & 910 \\
-1 & 50 & 235 & 335 & 520 & 620 & 805 & 905 \\
1 & 45 & 240 & 330 & 525 & 615 & 810 & 900 \\
3 & 40 & 245 & 325 & 530 & 610 & 815 & 895 \\
5 & 35 & 250 & 320 & 535 & 605 & 820 & 890 \\
7 & 30 & 255 & 315 & 540 & 600 & 825 & 885 \\
9 & 25 & 260 & 310 & 545 & 595 & 830 & 880 \\
11 & 20 & 265 & 305 & 550 & 590 & 835 & 875 \\
\hline
\end{tabular}

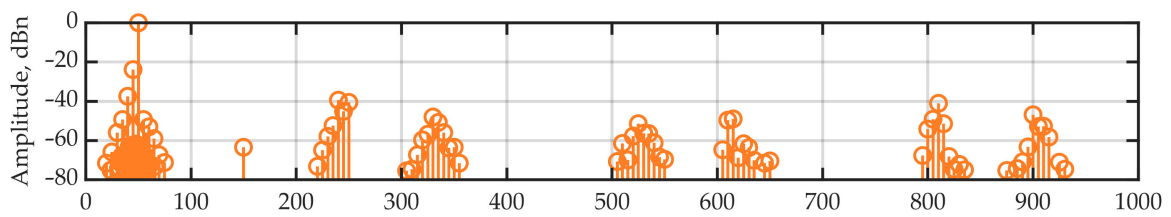

(a)

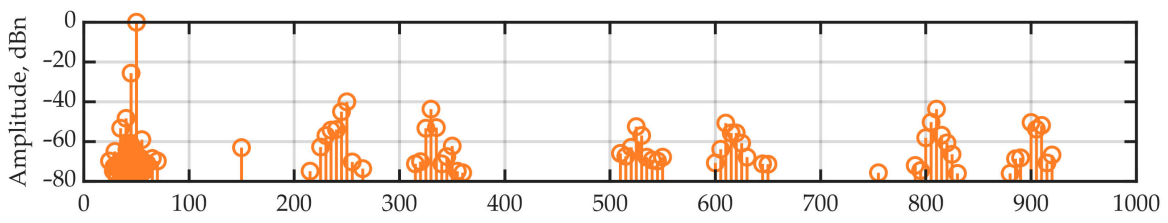

(b)

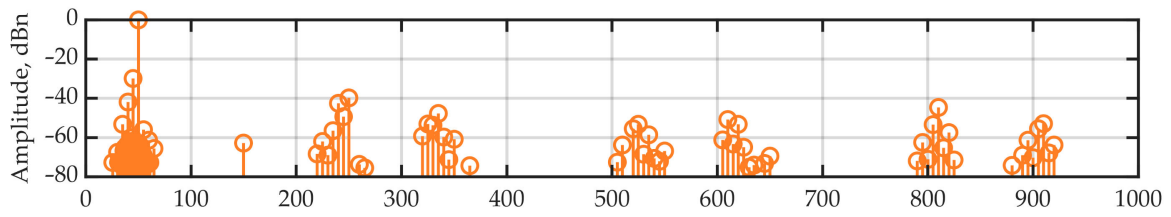

(c)

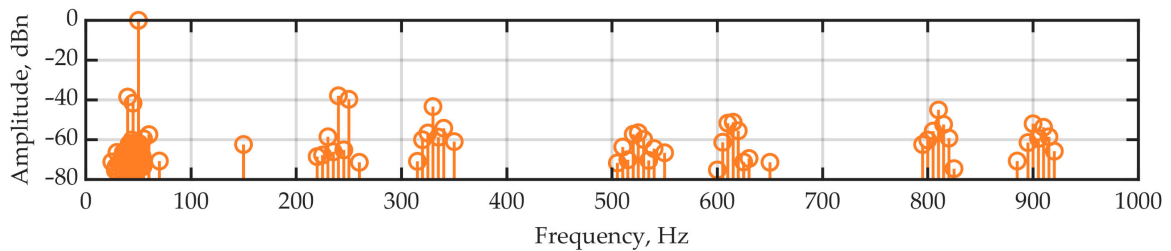

(d)

Figure 4. Spectrums of stator current for two completely broken rotor bars with the various mutual arrangement: (a) Two bars go consecutively, (b) two bars are located through one serviceable bar, (c) two bars are located through two serviceable, (d) two broken bars are located through three serviceable.

It should be noted that the observed pattern was also manifested for $v>19$ but in this study we were limited to the selected frequency range because the simulation showed that the amplitudes of higher-frequency harmonics were relatively small.

By comparing the resulting formulas with Equations (1) and (2) we can make two conclusions. First, Equation (3) does not contradict Equation (2), but it is more general and describes the frequencies that were found in $[12,13]$. On the other hand, there was no clear dependence on the number of pairs of poles in Equation (3) that is confirmed experimentally. Therefore, Equation (3) describes different harmonics than were discovered in [9-11]. 


\subsubsection{The Case of Several Fault Bars}

The problem of simulation of the breakage which included several fault bars possessed the uncertainty associated with the mutual arrangement of serviceable and faulty bars.

Figure 4 shows the spectrum of current through two completely broken bars for various locations of these bars.

To identify the influence of the relative position of faulty bars on the current spectrum of stator winding we made the following cases:

- Two consecutive broken bars;

- Two broken bars located through one serviceable;

- Through two serviceable; and

- Through three serviceable.

Let us compare Figures $2 \mathrm{~d}$ and $4 \mathrm{a}$. One can notice a significant increase in all harmonics when two broken bars go consequently. When changing the mutual location of broken bars we obtained an irregular change in the spectrum. Some harmonics increased and some others reduced their amplitudes. The case of two fault bars, between which three serviceable ones were situated (Figure $4 \mathrm{~d}$ ), was here of greatest interest. In this case, the amplitude of the base frequency of the first group $f_{1}(1-2 s)$ had significantly decreased. Comparing Figures $2 \mathrm{c}$ and $4 \mathrm{~d}$, one can see that if we only analyze the harmonic $f_{1}(1-2 s)$, then such fault appears to be equivalent to a break of $50 \%$ of the bar.

\subsection{Real-Site Verification}

\subsubsection{Experimental Study}

The experimental verification was carried out on a specially designed setup. Figure 5a shows the structure of the setup with the two-machine unit. Load motor M2 is connected to a frequency converter. The investigated (M1) and load (M2) machines were induction motors AIR9012 ("Elektodvigatel" Electrical Engines Factory, Mogilev, Belarus). Consider the M1 engine connected via TV1 autotransformer to the power network. During the experiment, the load engine accelerated the two-machine unit to the nominal idling speed, and then the autotransformer set the nominal voltage on the engine under study. After that, the frequency of the power supply voltage of the load motor decreased and, when it passed to the generator mode, it created a moment on the shaft of the engine under investigation.

The generated power was dissipated through the transistor $V M 1$ on the reset resistor R1. To minimize the effect of the rectifier on the network and, consequently, the investigated engine, the $L C$ filter L1-L3, C1-C3 was used. The shaft rotation speed was controlled by an optical tachometer.

The spectrums that are given in Figure 6 and thereafter were obtained with the spectral analysis algorithm [22] as was stated before.

One can see from Figure $6 a$ that the algorithm [22] extracted frequencies, specified their amplitudes, and filtered noise. You can also see that these frequencies were hidden by the side effects of the fast Fourier transform, e.g., this can be observed at $225 \mathrm{~Hz}$.

\subsubsection{Simulation of The Development of A Rotor Bar Break}

One can see the initial condition of the asynchronous motor rotor in Figure 7a. To simulate the development of a rotor bar break we introduced the artificial defect (Figure 7b). For minimizing the de-balancing effects we placed the defect between short-circuit ring and rotor bar connection. 


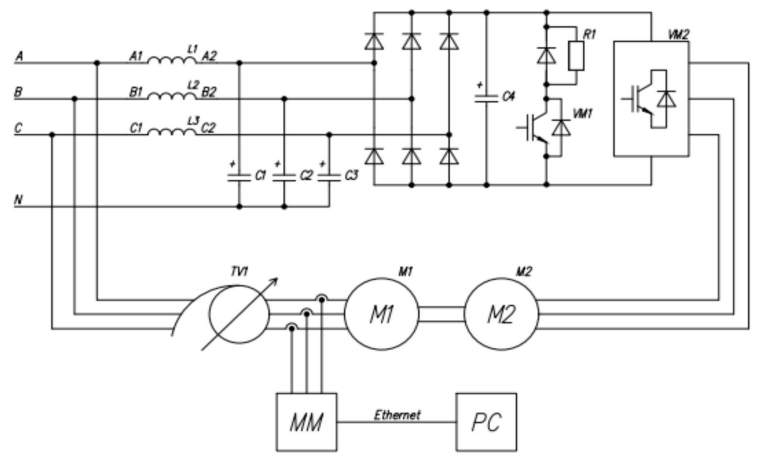

(a)

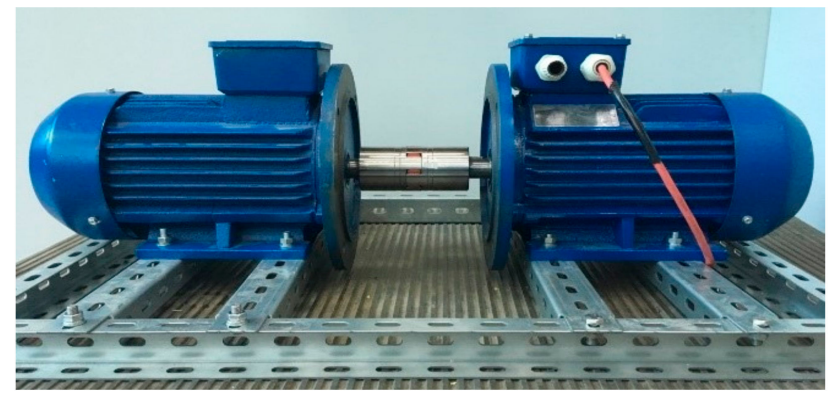

(b)

Figure 5. (a) Diagram of the experimental setup, (b) The appearance of the setup.

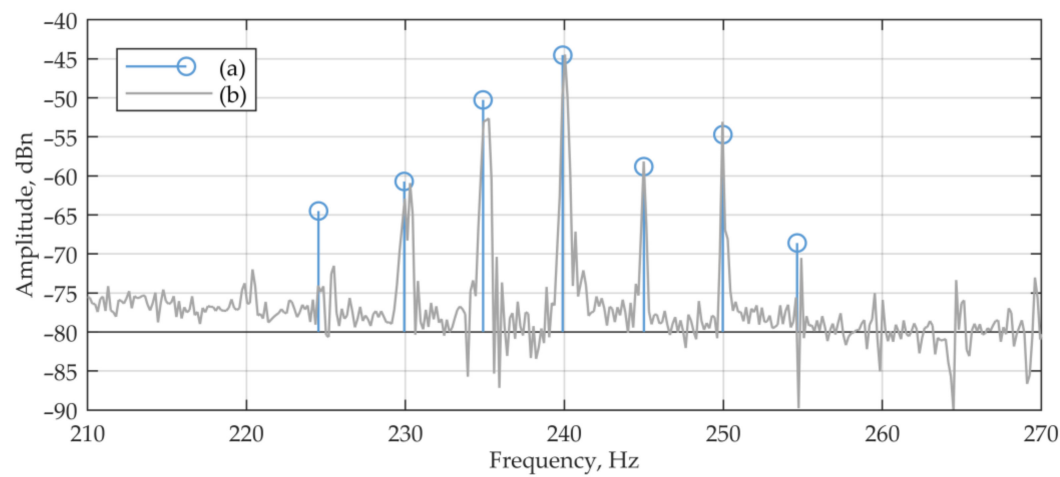

Figure 6. The stator current spectrum when two rotor bars are broken, obtained by the method of: (a) Spectral analysis algorithm [22], (b) Fast Fourier transform.

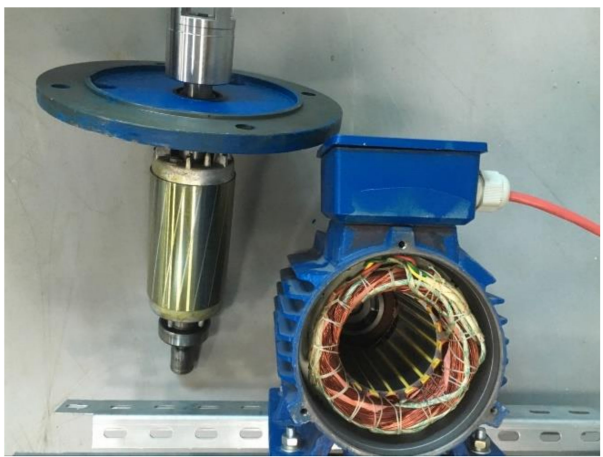

(a)

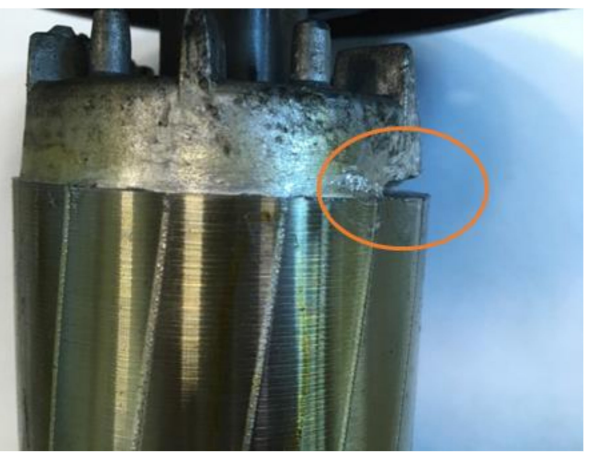

(b)

Figure 7. The images of rotor induction motor under investigation: (a) Initial condition, (b) Fault of $100 \%$ section of two bars. 
The measurements discovered that there were some detected harmonics even in the initial rotor condition (Figure 8a). In general, this was caused by the asymmetry of the rotor chain. This phenomenon can be explained by the appearance of lacunae when aluminum was poured into the slots of rotor's magnetic core.

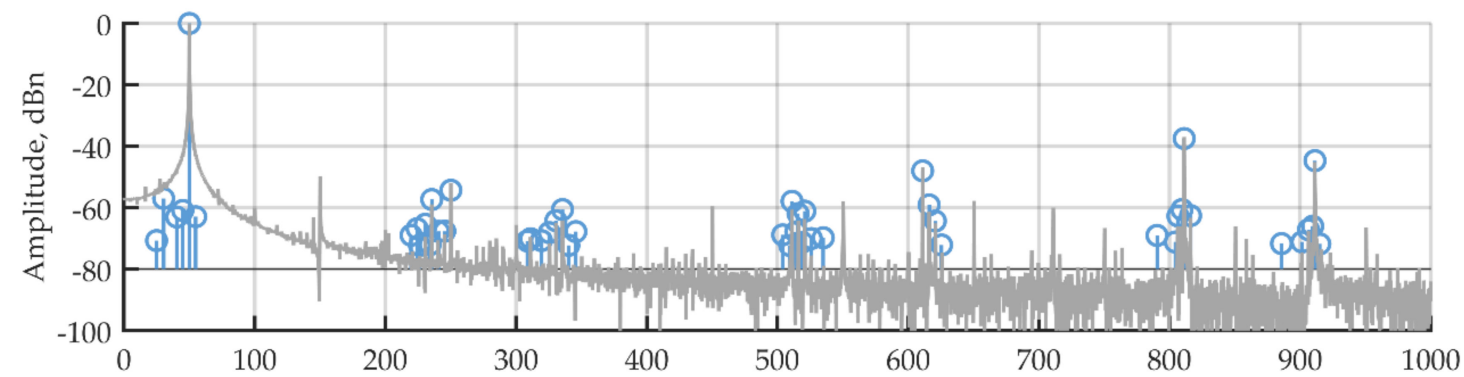

(a)

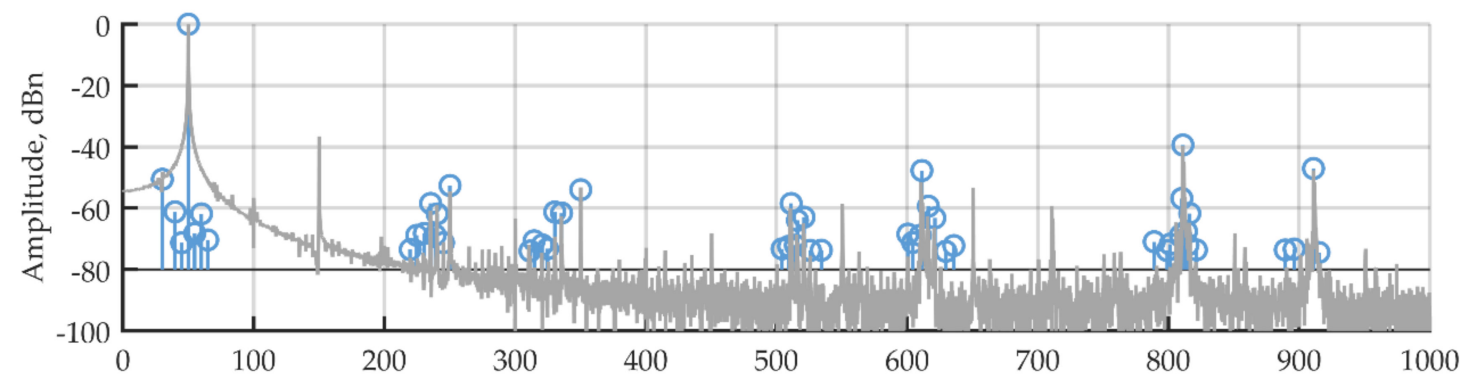

(b)

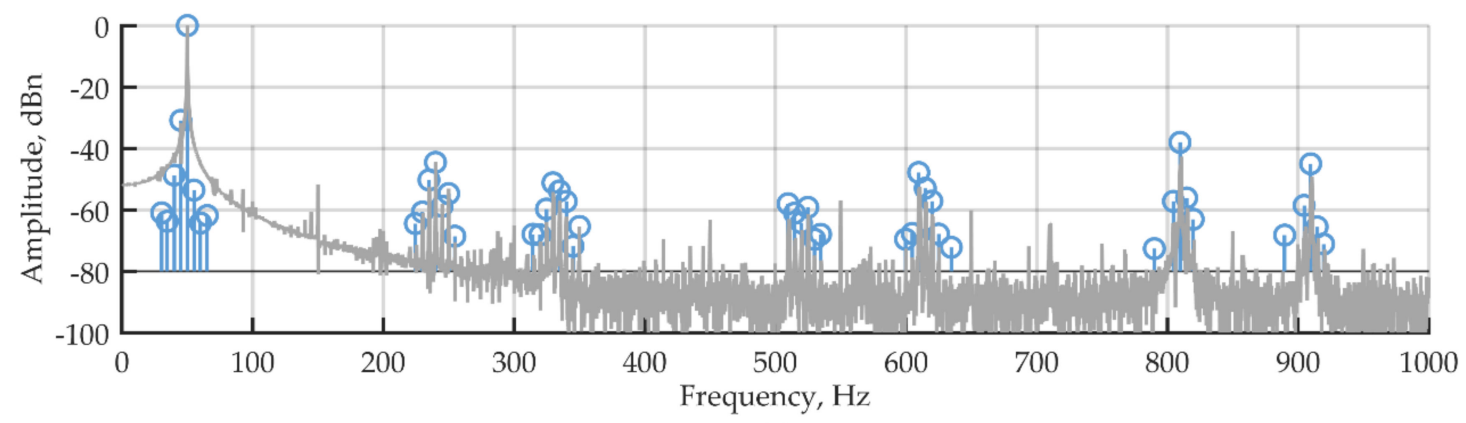

(c)

Figure 8. The current spectrum of the stator with different degrees of rotor fault: (a) Initial rotor state, (b) $100 \%$ fault of bar section, (c) Two bars broken at $100 \%$ cross-section.

Experiments with a slightly faulty rotor did not lead to noticeable changes in the current spectrum. The first noticeable changes occurred when the single bar was completely broken (Figure $8 b$ ). With the complete failure of two bars, the significant changes in the spectrum were observed (Figure 8c).

\section{Discussion}

The behavior of the spectrum, when a defect was introduced into a real engine, resembled the case shown in Figure $4 \mathrm{~d}$. The fault of the single bar led us to the decrease in harmonic $f_{1}(1-2 s)$, while other frequencies corresponding to Equation (3) were marked by slightly nonsystemic changes.

In conjunction with the presence of harmonics of rotor bar fault in the initial state, this is an additional argument in favor of the assumption that there are manufacturing defects, for example, the lacunae formed by pouring aluminum into the slots of the rotor magnetic core.

The results of our study were consistent with the results of previous works [12,13]. The obtained empirical formula, Equation (3), generalized the formula, Equation (1). The harmonic $f_{1}(1-2 s)$ was also a special case of Equation (3). 
Most of practical interest arose from the fact that a large number of frequencies located in the interval from 0 to $1000 \mathrm{~Hz}$ respond to rotor bars' fault by changing their amplitude. Large numbers of reference frequencies allow reducing the possibility of false alarms in real systems, and their large range will increase the noise immunity of the algorithm.

Comparing modeling results and results of experiments, for example, Figures $4 \mathrm{a}$ and $8 \mathrm{c}$, it can be concluded that FEM modeling allows one to simulate quite accurately processes occurring in induction motor if rotor bars are broken.

\section{Conclusions}

In this study, we proposed a versatile empiric technique to obtain frequencies for spectrum markers of damaged rotor bars using simulation analysis. The theoretical results were verified through the experiment with the real induction motor under load, including broken bars case.

Comparison of simulation results of two bars fault with different relative positions shows that different superposition of rotor defects causes various effects on each of the identified harmonics. Thus, we can assume that each state of the rotor corresponds to some individual set of harmonics. If this hypothesis is true, then using the machine learning algorithms one can create a neural network algorithm that can recognize the state of each bar by analyzing the current spectrum of an induction engine. Further research in this area will be directed to a formal or statistical proof of this hypothesis.

The proposed approach can be applied to the detection and analysis of isolation damage in stator winding as well as for the estimation of the static and dynamic eccentricity of the rotor. If it will be possible to establish the connection between ANSYS Mechanical and ANSYS Maxwell software packages, one can estimate the wearing of the bearings by our approach as well.

Author Contributions: Data curation, M.V.; formal analysis, D.B.; investigation, G.B. and D.B.; methodology, M.V.; project administration, E.N., M.V., and D.B.; resources, E.N. and V.O.; software, G.B. and V.O.; supervision, E.N. and D.B.; validation, G.B. and M.V.; visualization, G.B. and V.O.; writing-original draft, G.B; writing-review \& editing, E.N., V.O., and D.B. All authors have read and agreed to the published version of the manuscript.

Funding: This research received no external funding

Conflicts of Interest: The authors declare no conflict of interest.

\section{References}

1. Escaler, X.; Mebarki, T. Full-Scale wind turbine vibration signature analysis. Machines 2018, 6, 63. [CrossRef]

2. Luwei, K.C.; Yunusa-Kaltungo, A.; Sha'aban, Y.A. Integrated fault detection framework for classifying rotating machine faults using frequency domain data fusion and artificial neural networks. Machines 2018, 6, 59. [CrossRef]

3. Villarroel, A.; Zurita, G.; Velarde, R. Development of a low-cost vibration measurement system for industrial applications. Machines 2019, 7, 12. [CrossRef]

4. Hsueh, Y.; Ittangihala, V.R.; Wu, W.B.; Chang, H.C.; Kuo, C.C. Condition monitor system for rotation machine by CNN with recurrence plot. Energies 2019, 12, 3221. [CrossRef]

5. Wang, Z.; Yang, J.; Li, H.; Zhen, D.; Xu, Y.; Gu, F. Fault identification of broken rotor bars in induction motors using an improved cyclic modulation spectral analysis. Energies 2019, 12, 3279. [CrossRef]

6. Thomson, W.T.; Fenger, M. Current signature analysis to detect induction motor faults. IEEE Ind. Appl. Mag. 2001, 7, 26-34. [CrossRef]

7. Nandi, S.; Toliyat, H.A.; Li, X. Condition monitoring and fault diagnosis of electrical motors-A review. IEEE Trans. Energy Convers. 2005, 20, 719-729. [CrossRef]

8. Kliman, G.B.; Koegl, R.A.; Stein, J.; Endicott, R.D.; Madden, M.W. Noninvasive detection of broken rotor bars in operating induction motors. IEEE Trans. Energy Convers. 1988, 3, 873-879. [CrossRef]

9. Henao, H.; Demian, C.; Capolino, G.A. A frequency-domain detection of stator winding faults in induction machines using an external flux sensor. IEEE Trans. Ind. Appl. 2003, 39, 1272-1279. [CrossRef] 
10. Henao, H.; Razik, H.; Capolino, G.A. Analytical approach of the stator current frequency harmonics computation for detection of induction machine rotor faults. IEEE Trans. Ind. Appl. 2005, 41, 801-807. [CrossRef]

11. Martinez, J.; Belahcen, A.; Arkkio, A. Broken bar indicators for cage induction motors and their relationship with the number of consecutive broken bars. IET Electr. Power Appl. 2013, 7, 633-642. [CrossRef]

12. Ghorbanian, V.; Faiz, J. A survey on time and frequency characteristics of induction motors with broken rotor bars in line-start and inverter-fed modes. Mech. Syst. Sig. Process 2015, 54, 427-456. [CrossRef]

13. Gyftakis, K.N.; Antonino-Daviu, J.A.; Garcia-Hernandez, R.; McCulloch, M.D.; Howey, D.A.; Marques Cardoso, A.J. Comparative experimental investigation of broken bar fault detectability in induction motors. IEEE Trans. Ind. Appl. 2016, 52, 1452-1459.

14. Zhukovskiy, Y.; Koteleva, N. Diagnostics and evaluation of the residual life of an induction motor according to energy parameters. J. Phy. Conf. Ser. 2018, 1050, 012106. [CrossRef]

15. Zhukovskiy, Y.; Koteleva, N. Automated system for definition of life-cycle resources of electromechanical equipment. IOP Conf. Ser. Mater. Sci. Eng. 2017, 177, 012014. [CrossRef]

16. Zhukovskiy, Y.; Koteleva, N. Method of data storing, collection and aggregation for definition of life-cycle resources of electromechanical equipment. IOP Conf. Ser. Earth Environ. Sci. 2017, 87, 032057. [CrossRef]

17. Zhukovskiy, Y.L.; Korolev, N.A.; Babanova, I.S.; Boikov, A.V. The prediction of the residual life of electromechanical equipment based on the artificial neural network. IOP Conf. Ser. Earth Environ. Sci. 2017, 87, 032056. [CrossRef]

18. Tang, J.; Yang, Y.; Chen, J.; Qiu, R.; Liu, Z. Characteristics analysis and measurement of inverter-fed induction motors for stator and rotor fault detection. Energies 2020, 13, 101. [CrossRef]

19. Li, H.; Wang, Z.; Zhen, D.; Gu, F.; Ball, A. Modulation sideband separation using the teager-kaiser energy operator for rotor fault diagnostics of induction motors. Energies 2019, 12, 4437. [CrossRef]

20. Tang, J.; Chen, J.; Dong, K.; Yang, Y.; Lv, H.; Liu, Z. Modeling and evaluation of stator and rotor faults for induction motors. Energies 2020, 13, 133. [CrossRef]

21. Gyftakis, K.N.; Spyropoulos, D.V.; Kappatou, J.C.; Mitronikas, E.D. A novel approach for broken bar fault diagnosis in induction motors through torque monitoring. IEEE Trans. Energy Convers. 2013, 28, 267-277. [CrossRef]

22. Baranov, G.D.; Matus, K.I.; Vaganov, M.A.; Bubnov, E.A. Spectral analysis algorithm for the diagnosis of electrical machines. In Proceedings of the 2019 IEEE Conference of Russian Young Researchers in Electrical and Electronic Engineering (EIConRus), Saint Petersburg and Moscow, Russia, 28-31 January 2019; 424-429. 